\title{
TRIMETHOPRIM ADSORPTION ONTO PILLARED CLAY USING A FULL FACTORIAL DESIGN
}

\author{
C. B. VIDAL ${ }^{1}$, G.S.C. RAULINO ${ }^{1}$, D.Q. MELO $^{2}$, G.P. PESSOA ${ }^{2}$, L.S. SILVA ${ }^{2}$, A.B. SANTOS ${ }^{1}$ e \\ R.F NASCIMENTO2 \\ ${ }^{1}$ Universidade Federal do Ceará, Departamento de Engenharia Hidráulica e Ambiental \\ ${ }^{2}$ Universidade Ferderal do Ceará, Departamento de Química Analítica e Físico-Química \\ E-mail para contato: carlab.vidal@gmail.com
}

\begin{abstract}
Batch adsorption experiments were carried out in order to evaluate the maximum adsorption conditions of pharmaceutical Trimethoprim from real wastewater on pillared clay using a full factorial design. The five factors were temperature, the initial $\mathrm{pH}$ of the solution, initial concentration, agitation and dosage of adsorbent. The optimization of the factors to obtain maximum adsorption was carried out by incorporating effect plots, normal probability plots, interaction plots, analysis of variance (ANOVA), Pareto charts, surface plots, and contour plots. The statistical design experiments, designed to reduce the total number of experiments required, indicated that, within the selected conditions, all the parameters influenced at a significance level of 5\%. In addition, some of the possible interactions between these parameters also influenced the adsorption process, especially those that were of first order. A regression model was suggested and fitted the experimental data very well.
\end{abstract}

\section{INTRODUCTION}

The escalating problem in pharmaceuticals and their metabolites water pollution has recently caught global attention due to its environmental and health hazards ( $\mathrm{Li}$ et al., 2013). The main concern regarding the pharmaceuticals as pollutants is that their biological activity will lead to adverse effects on aquatic ecosystems). These compounds are not completely removed by conventional wastewater treatment systems due to their high resistance to biodegradation (DeRudder et al., 2004; Fukahori et al., 2011) and have been also detected in seawater. Their presence in such ecosystem is attributed to the transport of contaminated wastewater effluent by rivers into larger water bodies such as oceans and seas (Pessoa et al., 2012). To reduce the potential risk caused by these compounds in treated wastewater discharged to aquatic environments, their removal is considered as an important technological challenge.

Adsorption is one of the most promising techniques used to remove pharmaceuticals from water (Fukahori et al., 2011). Among the adsorbents for the decontamination of water, the clay minerals are often selected owing to their low cost and its preference to adsorb specific contaminants (Jalil et al., 2013). Pillared clays have high permanent porosity obtained by separating the clay sheets by a molecular prop or pillaring agent. They are prepared by exchanging the native cations of the parent 


\section{9 a 22 de outubro de 2014 \\ Florianópolis/SC}

clay with partially hydrated polymeric or oligomeric metal cation complexes which, upon heating, undergo dehydration/dehydroxylation resulting in thermally stable pillars composed of metal oxide cluters (Gyftopoulou et al., 2005).

Instead of the traditional one-variable-at-a-time experiments which were used by the majority of previous researchers to determine the individual effect of various factors on adsorption processes, factorial design technique can be employed to reduce the number of experiments, time and overall research cost (Saadat and Jashni, 2011). The factorial design method determines which factors have significant effects on a response as well as how the effect of one factor varies according to the level of the other factors (Passos et al., 2006).

The main objectives of this work were to investigate the effect of $\mathrm{pH}$, adsorbent dose, initial trimethoprim (TMP) concentration, agitation and temperature on the adsorption of TMP onto pillared Mt to optimize the conditions for TMP removal.

\section{MATERIALS AND METHODS}

Montmorillonite was supplied from Bentonisa of Brazil, based in Campina Grande, Brazil. The cation exchange capacity (CEC) of Mt is $718 \mathrm{mmol} / 100 \mathrm{~g}$. It was estimated using the ammonium acetate method (Vidal et al., 2012).

The pillaring agent was prepared by adding dropwise $50 \mathrm{~mL}$ of tin chloride, $\mathrm{SnCl}_{2}$ (II) 0.4 mol. $\mathrm{L}^{-1}$ to $50 \mathrm{~mL}$ of $0.4 \mathrm{~mol} . \mathrm{L}^{-1} \mathrm{KOH}$ with continuous steering. Mt $(5.0 \mathrm{~g})$ was well dispersed in 400 $\mathrm{mL}$ of deionized and then $100 \mathrm{~mL}$ of pillaring agent was added into the clay suspension. The mixture reaction was stirred at $60{ }^{\circ} \mathrm{C}$ for $24 \mathrm{~h}$. The resulting suspension was centrifuged and washed several times with deionized water, dried at $80^{\circ} \mathrm{C}$ and calcined at $500{ }^{\circ} \mathrm{C}$ for $3 \mathrm{~h}$.

A general factorial design (STATGRAPHICS Centurion, StatPoint technologies, Inc, VA 20186, USA) consisting of $32+3$ (central points) experimental trials have been designed. In order to determine the factors that influence the removal of TMP by pillared Mt and to investigative the interaction effects of various parameters, a central composite design (CCD), and face centred model was chosen. Five factors, namely, $\mathrm{pH}$, adsorbent dose, initial concentration of TMP, agitation and temperature were varied at three levels as shown in Table 1. Analysis of variance (ANOVA) was carried out to determine any significant differences $(\mathrm{P}<0.05)$ among the applied treatments.

Table 1 - Experimental ranges and levels of the factors studied in the factorial design.

\begin{tabular}{|c|c|c|c|c|}
\hline Factor & Coded Symbol & \multicolumn{3}{|c|}{ Range and level } \\
\hline & & -1 & 0 & +1 \\
\hline Temperature $\left({ }^{\circ} \mathrm{C}\right)$ & $\mathrm{A}$ & 25 & 45 & 65 \\
\hline Agitation $(\mathrm{rpm})$ & $\mathrm{B}$ & 100 & 200 & 300 \\
\hline Initial TMP concentration $(\mathrm{mg} / \mathrm{L})$ & $\mathrm{C}$ & 5 & 55 & 105 \\
\hline Adsorbent dose $(\mathrm{mg})$ & $\mathrm{D}$ & 100 & 200 & 300 \\
\hline $\mathrm{pH}$ & $\mathrm{E}$ & 3 & 6 & 9 \\
\hline
\end{tabular}




\section{9 a 22 de outubro de 2014 \\ Florianópolis/SC}

The adsorptions of TMP were studied using a batch procedure and results were indicated in the form of adsorption capacity (Q) of TMP by pillared Mt, as shown in Equation 1. For each run, weighted amounts of adsorbent were added to glass flasks containing $200 \mathrm{~mL}$ of TMP in doped real wastewater and $\mathrm{pH}$ was adjusted to the desired value using $0.1 \mathrm{M} \mathrm{HCl}$ or $\mathrm{NaOH}$ solution as needed. The flasks were agitated in an incubated rotatory shake for $3 \mathrm{~h}$. The suspension were then filtered and analyzed in HPLC.

$$
Q=\frac{V *\left(C_{\mathrm{i}}-C_{f}\right)}{w}
$$

Where $\mathrm{Q}$ is the amount of EDCs adsorbed (mg) per $\mathrm{g}$ of pillared $\mathrm{Mt}, \mathrm{V}$ is the volume of solution (L), $\mathrm{Ci}$ is the initial EDCs concentration $(\mathrm{mg} / \mathrm{L}), \mathrm{Cf}$ is the final EDCs concentration $(\mathrm{mg} / \mathrm{L})$ and $\mathrm{w}$ is the weight of adsorbent $(\mathrm{g})$.

\section{RESULTS AND DISCUSSION}

Factors that influence the adsorbed quantity of TMP adsorbed onto Pillared Mt were evaluated by using factorial plots: main effect, interaction effect, the Pareto chart plot, normal probability plots, the surface plot, and the contour plot. ANOVA and P-value significant levels were used to check the significance of the effect on Q. The main effect and interactions were also observed in the Pareto chart plot. Main, interaction effect, coefficients of the model, standard deviation of each coefficient, and probability for the full 25 factorial designs were presented in Table 1.

The ANOVA table partitions the variability in TMP into separate pieces for each of the effects. It then tests the statistical significance of each effect by comparing the mean square against an estimate of the experimental error. In this case, 6 effects have P-values less than 0.05 , indicating that they are significantly different from zero at the $95.0 \%$ confidence level, which was temperature, agitation, initial concentration, adsorbent dose, temperature-Initial concentration interaction (AB) and Initial concentration and $\mathrm{pH}$ interaction $(\mathrm{CE})$. The positive values of these effects reveal that the increase of these parameters increased $\mathrm{Q}$. Conversely, negative values of the effects decreased the response (Q). According to Table 1, A, D, E, AB, AC, AE, BC, BD, CD e CE had a negative effect on $\mathrm{Q}$, while $\mathrm{B}, \mathrm{C}, \mathrm{AD}, \mathrm{BE}$ e $\mathrm{DE}$ had a positive effect.

Table 1 - Estimated effects for TMP (mg/g) and Analysis of Variance for TMP.

\begin{tabular}{|l|l|l|l|l|l|l|l|}
\hline & \multicolumn{2}{|l|}{ Effect Estimate } & \multicolumn{5}{|c|}{ ANOVA } \\
\hline & Estimate & Stnd. Error & Sum of Squares & Df & Mean Square & F-Ratio & P-Value \\
\hline average & 9.63857 & 0.891262 & & & & & \\
\hline A:Temperature & -6.805 & 1.86421 & 370.464 & 1 & 370.464 & 13.32 & 0.0017 \\
\hline B:Agitation & 4.41375 & 1.86421 & 155.85 & 1 & 155.85 & 5.61 & 0.0287 \\
\hline C: Initial concentration & 12.1163 & 1.86421 & 1174.43 & 1 & 1174.43 & 42.24 & 0.0000 \\
\hline
\end{tabular}




\begin{tabular}{|l|l|l|l|l|l|l|l|}
\hline D: Adsorbent dose & -5.605 & 1.86421 & 251.328 & 1 & 251.328 & 9.04 & 0.0073 \\
\hline E:pH & -2.99125 & 1.86421 & 71.5806 & 1 & 71.5806 & 2.57 & 0.1251 \\
\hline AB & -1.5825 & 1.86421 & 20.0344 & 1 & 20.0344 & 0.72 & 0.4065 \\
\hline AC & -5.9825 & 1.86421 & 286.322 & 1 & 286.322 & 10.30 & 0.0046 \\
\hline AD & 0.87375 & 1.86421 & 6.10751 & 1 & 6.10751 & 0.22 & 0.6446 \\
\hline AE & -0.415 & 1.86421 & 1.3778 & 1 & 1.3778 & 0.05 & 0.8262 \\
\hline BC & -0.11875 & 1.86421 & 0.112813 & 1 & 0.112813 & 0.00 & 0.9499 \\
\hline BD & -3.8025 & 1.86421 & 115.672 & 1 & 115.672 & 4.16 & 0.0555 \\
\hline BE & 3.21375 & 1.86421 & 82.6255 & 1 & 82.6255 & 2.97 & 0.1010 \\
\hline CD & -0.0925 & 1.86421 & 0.06845 & 1 & 0.06845 & 0.00 & 0.9609 \\
\hline CE & -7.07625 & 1.86421 & 400.587 & 1 & 400.587 & 14.41 & 0.0012 \\
\hline DE & 1.9075 & 1.86421 & 29.1085 & 1 & 29.1085 & 1.05 & 0.3191 \\
\hline
\end{tabular}

Interesting the $\mathrm{pH}$ had no effect at the $95 \%$ confidence level, this could due because at $\mathrm{pH} 3-10$ the pillared Mt has a negative net surface charge (pHpzc 3) (graph not shown). On the other hand, at pH 9 all TMP species are neutral which would implicate that hydrophobic interactions between the pillars of pillared Mt and neutral species, whereas at $\mathrm{pH} 3$, we have TMP protonated species (NH+) adsorb on pillared Mt could be following electrostatic interactions. In addition TMP has two amine sites in its molecule, which could favor the Lewis acid-base interaction, where $-\mathrm{NH} 2$ of TMP is the Lewis-base and the oxygen-containing groups of pillared Mt serve as Lewis-acids, may be the mechanism of the TMP adsorption. The presence of lone pairs of electrons on nitrogen atoms produce dipolar moment for TMP. Negative charges are close to nitrogen atoms and the presence of the polar oxygen groups on the pillared Mt surface and lone pair of electrons on the oxygen atoms may be also the reason for surface specific interactions between the oxygen surface groups of pillared Mt and TMP molecules.

The R-Squared statistic indicates that the model as fitted explains $84.9 \%$ of the variability in TMP. The adjusted R-squared statistic, which is more suitable for comparing models with different numbers of independent variables, is $72.9 \%$. The standard error of the estimate shows the standard deviation of the residuals to be 5.27. The mean absolute error (MAE) of 3.05 is the average value of the residuals.

In this way, the TMP uptake by pillared Mt could be expressed using the following Equation:

$\mathrm{Q}=-0.4978+0.0506 \mathrm{~A}+0.0464 \mathrm{~B}+0.4015 \mathrm{C}-0.0184 \mathrm{D}-0.7527 \mathrm{E}-0.0004 \mathrm{AB}-0.003 \mathrm{AC}+$ $0.0002 \mathrm{AD}-0.0035 \mathrm{AE}-0.00001 \mathrm{BC}-0.0002 \mathrm{BD}+0.0054 \mathrm{BE}-0.00001 \mathrm{CD}-0.0236 \mathrm{CE}+0.0032 \mathrm{DE}$

The main effect plots were generated to represent the results of the regression analysis and represent deviations of the average between the high and low levels for each factor. When the effect of a factor is positive, $Q$ increases as the factor changes from low to high levels. In contrast, if the effects are negative, a reduction in (Q) occurs for high level of the same factor (Ponnusami et al., 
2007). From Figure 1A, it is inferred that the larger the vertical line, the larger the change in $Q$ when changing from level -1 to level +1 . It should be pointed out that the statistical significance of a factor is directly related to the length of the vertical line (Palanikumar and Dawim, 2009; Bingol et al., 2010). The effects of temperature, $\mathrm{pH}$ and adsorbent dose factors are negative, that is, a decrease of $\mathrm{Q}$ is observed when the factor changes from low to high, resulting in a higher mean $Q$ at their low level, compared to that at the high level. Q decreases as temperature increases due to the weakening of adsorptive forces between the active sites of the adsorbent. For the Co and agitation the opposite is true. In addition, Co had a greater effect on Q, as is evident by the longer vertical line.

The relative importance of the main effects and their interactions was also observed on the Pareto chart (Figure 1B). A student's t-test was performed to determine whether the calculated effects were significantly different from zero, these values for each effect are shown in the Pareto chart by horizontal columns (Ponnusami et al., 2007). For the 95\% confidence level and thirty-one degrees of freedom, the t-value is 2.04. The values that exceed a reference line, i.e., those corresponding to the 95\% confidence interval, are significant values (Mathialagan and Viraraghavan, 2005).
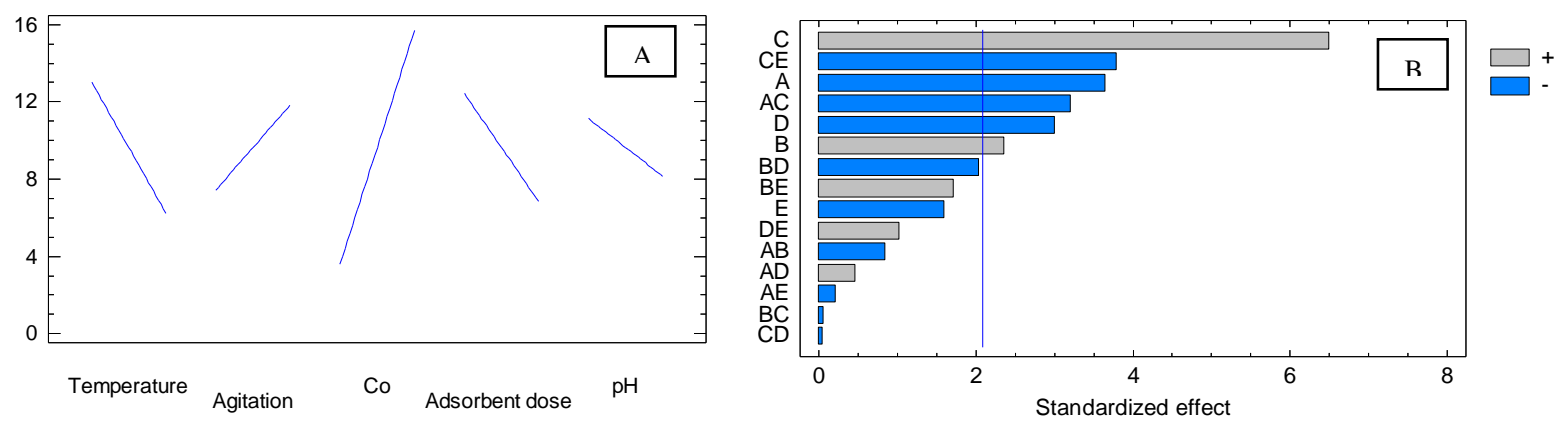

Figure 1 - Main effects plot for Q (A) and Pareto chart of the standardized effects (B).

The surface plots of the response functions are useful in understanding both the main and interaction effects of the factors (Arbizu and Luis Pérez, 2003). These plots can be obtained by computations using developed response models and adequate software. The response surface plots are reported in Figure 3 for the average Q. After performing a screening of factors using a full $2^{5}$ factorial design, the surface and contour plots of the response (Q) indicated the same results as observed in the interaction plot (Table 1). The contour plots are curved lines because the model contains the interactions of the factors $(\mathrm{AB}, \mathrm{AC}, \mathrm{AD}, \mathrm{AE}, \mathrm{BC}, \mathrm{BD}, \mathrm{BE}, \mathrm{CD}, \mathrm{CE}, \mathrm{DE})$ and reveal that the maximum values of $\mathrm{Q}$ required lower temperature, $\mathrm{pH}$, adsorbent dose and higher agitation and $\mathrm{Co}$ in agreement with the interaction graphs. 

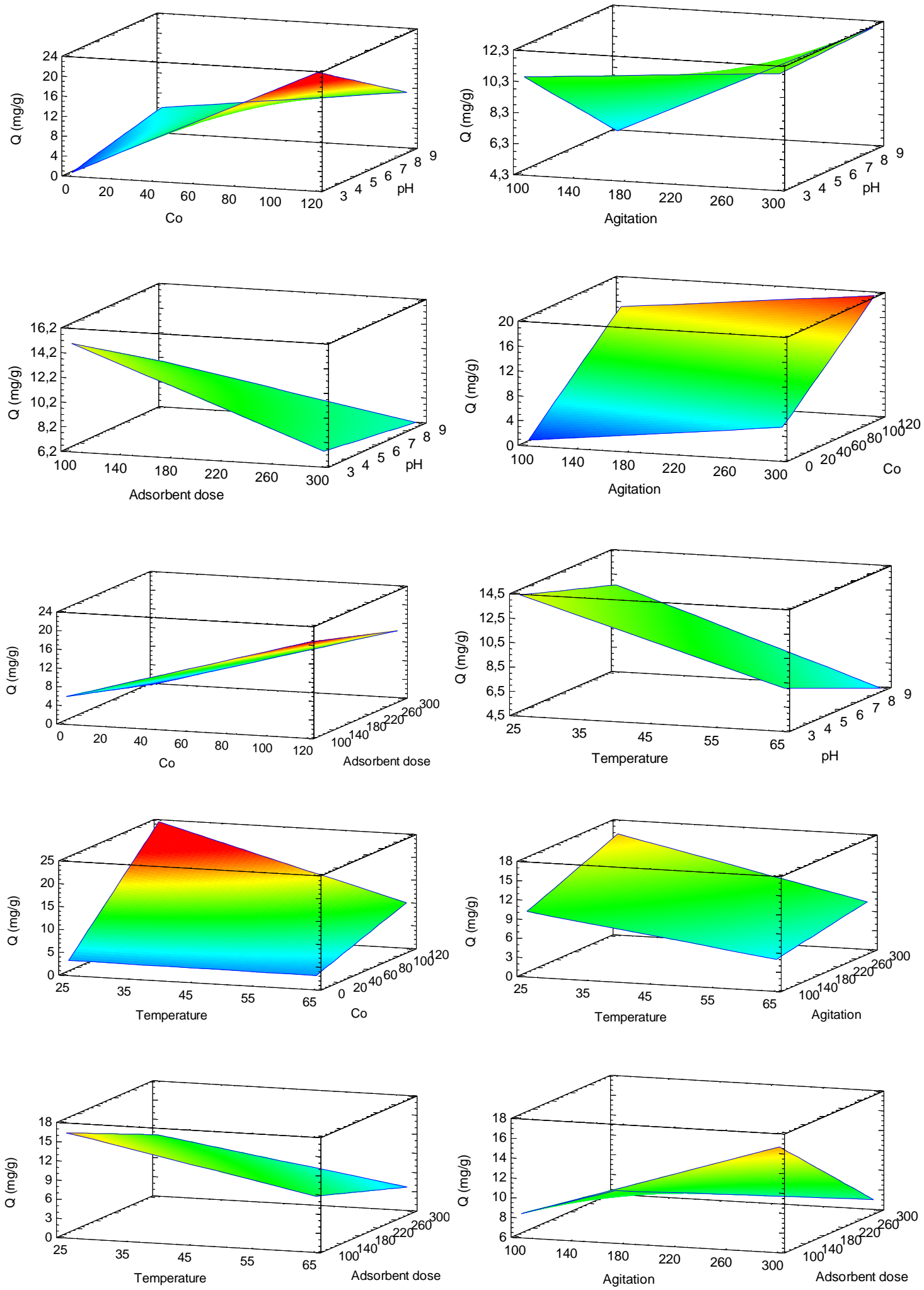


\section{9 a 22 de outubro de 2014 \\ Florianópolis/SC}

Figure 3- Surface plots of Q.

\section{CONCLUSIONS}

The statistical design of the experiments combined with techniques of regression was applied in optimizing the conditions of maximum adsorption of the TMP onto pillared Mt. The initial $\mathrm{pH}$ of the dispersion exerted the greatest influence on the amounts of TMP adsorbed Q. The factorial experiments demonstrated that $\mathrm{pH}-\mathrm{Co}$; Co-agitation; Co-Adsorbent dose and Temperature-Co interaction had more influence on $\mathrm{Q}$ than did the other interactions. Adsorbent dose, temperature and $\mathrm{pH}$ had a negative influence on $\mathrm{Q}$, is the validity of this study was limited to temperatures between 25 and $65{ }^{\circ} \mathrm{C}$, pH between 3 and 9, agitation between 100 and $300 \mathrm{rpm}$, Initial TPM concentration between 5 and $105 \mathrm{mg} / \mathrm{L}$ and adsorbent dose between 100 and $300 \mathrm{mg}$.

\section{REFERENCES}

JALIL, M.E.R.; VIEIRA, R.S.; AZEVEDO, D.; BASCHINI, M.; SAPAG. Improvement in the adsorption of thiabendazole by using aluminium pillared clays. Appl. Clay Sci., v. 71, p. 55-63, 2013.

FUKAHORI, S.; FUJIWARA, T.; ITO, R.; FUNAMIZU, N. pH-Dependent adsorption of sulfa drugs on high silica zeolite: Modeling and kinetic study. Desalination, v. 275, p. 237-242, 2011.

PESSOA, G.P.; DOS SANTOS, A.B.; SOUZA, N.C.; ALVES, J.A.C.; NASCIMENTO, R.F. Development of methodology to determine estrogens in wastewater treatment plants, Quim Nova, v.35, p. 968973, 2012.

DERUDDER, J., VAN DE WIELE, T., DHOOGE, W., COMHAIRE, F., VERSTRAETE, W. Advanced water treatment with manganese oxide for the removal of 17 $\alpha$-ethinyl estradiol (EE2), Water Res. v.38, p. 184-192, 2004.

GYFTOPOULOU, M.E., MILlAN, M., BRIDGWATER, A.V., DUGWELL, D., KANDIYOTI, R., HRILJAC, J.A. Pillared clays as catalysts for hydrocracking of heavy liquid fuels. Appl. Catal. A- Gen. v. 282, p. 205-214, 2005.

SAADAT, S.; KARIMI-JASHNI, A. Optimization of $\mathrm{Pb}$ (II) adsorption onto modified walnut shells using factorial design and simplex methodologies. Chem. Eng. J. v. 173, p.743-749, 2011.

PASSOS, C.G.; RIBASKI, F.S.; SIMON, N.M.; DOS SANTOS JR, A.A.; VAGHETTI, J.C.P.; BENVENUTTI, E.V.; LIMA, E.C. Use of statistical design of experiments to evaluate the sorption capacity of 7-amine-4-azaheptylsilica and 10-amine-4-azadecylsilica for $\mathrm{Cu}(\mathrm{II}), \mathrm{Pb}(\mathrm{II})$, and $\mathrm{Fe}(\mathrm{III})$ adsorption. $J$. Colloid Interf. Sci. v. 302, p. 396-407, 2006.

VIDAL, C. B.; RAULINO, G. S. C.; BARROS, A. L.; LIMA, A. C. A.; RIBEIRO, J. P.; PIRES, M. J. R.; NASCIMENTO, R. F. BTEX removal from aqueous solutions by HDTMA-modified Y zeolite. $J$. Environ. Manage. v. 112, p.178-185, 2012.

PONNUSAMI, V.; KRITHIKA, V.; MADHURAM, R.; SRIVASTAVA, S.N. Biosorption of reactive dye using acid-treated rice husk: factorial design analysis. J. Hazard. Mater. v. 142 p. 397-403, 2007. 
PALANIKUMAR, K., DAWIM, J.P. Assessment of some factors influencing tool wear on the machining of glass fibre-reinforced plastics by coated cemented carbide tools. J. Mater. Process. Technol. v. 209, p. 511-519, 2009.

MATHIALAGAN, T., VIRARAGHAVAN, T. Biosorption of pentachlorophenol by fungal biomass from aqueous solutions: a factorial design analysis. Environ. Technol. v. 6, p. 571-579, 2005.

ARBIZU, I.P., LUIS PÉREZ, C.J. Surface roughness prediction by factorial design of experiments in turning processes. J. Mater. Process. Technol. v. 143-144, p. 390-396, 2003.

BINGOL, D.; TEKIN, N.; ALKAN, M. Brilliant Yellow dye adsorption onto sepiolite using a full factorial design. Appl. Clay Sci. v. 50, p. 315-321, 2010. 